\title{
The Degree of Having Life Skills among the Hashemite University Students
}

\author{
Lina Z. Al-Qassem ${ }^{1}$, Ahmad M. Mahasneh ${ }^{1}$, Omar M. Mahasneh ${ }^{2}$, Zohair H. Al-Zoubi ${ }^{3} \&$ Omar T. Batayeneh $^{4}$ \\ ${ }^{1}$ Faculty of Educational Science, Hashemite University, Zarqa, Jordan \\ ${ }^{2}$ Al-Balqa Applied University, Jordan \\ ${ }^{3}$ Faculty of Educational Science, Hashemite University, Zarqa, Jordan \\ ${ }^{4}$ Faculty of Arts, Hashemite University, Zarqa, Jordan \\ Correspondence: Ahmad M. Mahasneh, Faculty of Educational Science, Hashemite University, Zarqa, Jordan. \\ E-mail: dahmadmahasneh1975@yahoo.com
}

\author{
Received: December 10, 2013 Accepted: January 10, 2014 Online Published: February 24, 2014 \\ doi:10.5539/res.v6n1p180 \\ URL: http://dx.doi.org/10.5539/res.v6n1p180
}

\begin{abstract}
The primary purpose of this study was to determine revealing the degree of possessing life skills among the Hashemite University students. The sample of the study consisted of (855) male and female students from different colleges, and this sample represents a percentage of $(6 \%)$ from the community of the study. A questionnaire related to life skills was utilized, containing (30) items distributed among 3 domains. Additionally, results indicated that the Hashemite University Students' possession degree of life skills was medium. The first rank was occupied by the skills of communication with others, followed by the academic skills, and in the last rank came the skills of decision making and problem solving. Also, the results revealed that that there were no statistically significant differences in the possession degree of life skills among the Hashemite University students ascribed to the variable of gender, and that there were statistically significant differences in the possession degree of communication and academic skills among the Hashemite University students ascribed to the variable of academic level. In addition, there were statistically significant differences in the possession degree of communication skills, academic skills and decision making and problem solving skills among the Hashemite University students ascribed to the variable of GPA.
\end{abstract}

Keywords: life skills, communication skills, academic skills, Hashemite University students

\section{Introduction}

The concept of life can be defined as a series of undefined and unclear situations. Thus, living in this life can't be within pre-set rules. That is why we find those people who are distinguished in their academic specialties usually fail in managing their daily life affairs. Although human beings are able to interact with life, they often fail in managing their life situations, and when they fail, they justify that weakly. Accordingly, the human being, because of his wisdom and ability of thinking and learning, was able to create civilizations and face problems. Hence, through thinking, the ability to learn and the realization of the importance of successful interaction with the daily life situations on the social and personal level, the individual can precede his success. So the individual's learning of the scientific basics and the basic skills needed for existing in this life has become a necessity that helps him getting to truth. Therefore, the concept of life skills appeared helping the individuals in dealing with their daily life situations according to scientific principles that are not purposeless (Alawiye, 1990). Based on that, the concept of life skills has become popular as a result of presenting the learner as the core of the process of learning and teaching by the constructive and cognitive theories. These theories stressed the necessity of taking care of the learner as well as improving all of his aspects: mental, physical and social so as to be able to cope with the surrounding environment (Mahasneh, 2013).

After reviewing the educational literature related to life skills, Danish \& Steven (1997) defined them as a group of behaviors and social and personal skills needed for dealing confidently and effectively with themselves, with others, with things and with the society. That is represented by the ability to take the right and proper decisions, assume the personal and social responsibilities, understand the self and the others, form positive relations with others, avoid crises and think creatively. Whereas the World Health Organization defined the concept as the 
abilities that enable the individuals to have positive behaviors that make them able to cope with and interact with the daily life requirements (Ministry of Education, 2007; Bellotti, 2005). Some researchers like Al-Khatatneh (2007), Bastian \& Veneta (2005), Behrman (2005) and Schneider (2004) defined it as the individuals' possessing of the skills of creative thinking, decision making, knowledge acquisition, responsibility bearing, communication, self-understanding and appreciation, and the ability to interact with others that enable them to deal with the multiple life requirements positively. The life skills express the desire, the awareness and the ability to solve social or personal life problems or facing daily challenges or conducting modifications and improvements in the style and quality of the individuals' or society's life (Khalil \& Al-Baz, 1999). On the other hand, Jones (1991) defined it as the group of processes or procedures through which the individual can solve a problem or face a challenge or modify his life.

Many classifications have been set for the life skills. Thus, UNICEF (2005) has classified the life skills into 3 categories: the $\mathbf{1}^{\text {st }}$ one is related to the skills of communication and relations with others, and it includes the skills of communication related to the relationships between people like (verbal/non verbal communication, good listening, expressing feelings, presenting notes and comments and receiving them), the skills of negotiation/rejection like (the skills of negotiation and conflict management, the skills of self-assertion, the skills of rejecting), the skills of emotional reincarnation like (understanding others and sympathizing with them, the ability to listen to the others' needs and circumstances, understanding them and expressing that), the skills of cooperation and team work like (showing respect for others' contributions and styles, self-assessment and contribution to the team), the skills of gaining support like (the skills of affecting others and convincing them) as well as the skills of encouraging or motivating. The $\mathbf{2}^{\text {nd }}$ category is related to the skills of decision making critical thinking, including the skills of decision making and problem solving like (the skills of gathering data, evaluating the future results of the current procedures for both the self and the others, identifying the alternative solutions for problems, the skills of analysis related to the effect of values, self attitudes and others' attitudes when having the emotive ), and the skills of critical thinking like (analyzing the partners' and media influence, analyzing attitudes, values, traditions and social beliefs as well as the factors affecting them, and identifying the related information and their resources). The $3^{\text {rd }}$ category which is related to the skills of dealing and self-management includes skills that would increase the interior control centre like (the skills of self-appreciation/confidence building), the skills of self-awareness including (the recognition of rights and influences, values and trends, weaknesses and strengths) the skills of goals identification, the skills of self-assessment/self-estimating assessment and self-control, the skills of feelings management like (managing anger taking up, dealing with sorrow and worry), the skills of dealing with loss, abuse, painful shocks, the skills of pressure dealing management like (time management, positive thinking, and the relaxation techniques).

As for the World Health Organization's classification, it classified the life skills into: the self, social and national responsibility, the communication skills, problem solving and decision making, critical thinking, creative thinking, team work, self-appreciation, self-awareness, reasonable use of resources, dealing with situations, conflict management and solving struggles, and acceptance of diversity, difference in views and the other opinion (Schneider, 2004).

A group of researchers, like Subhi, Omran \& Al-Shenawi (2001) classified the life skills into 2 categories. The $1^{\text {st }}$ one is related to the intellectual skills like reading, writing and doing math, communicating, making decisions, problem solving, time and effort management, self-control, controlling reactions, situations and crises management, and practicing creative critical thinking. Whereas the $2^{\text {nd }}$ category is associated with the practical skills such as taking care of the body, personal cleanliness, preparing food, reasonable use of the environment resources, reasonable consumption and other daily skills. Prince (1995) categorized them into: interacting with others, avoiding risks, dealing with social services, getting a job, good nutrition, practicing healthy habits, money management and reasonable consumption. Kovalik (2000) classified them into the skills of organizing and problem solving, contemplation, initiating, flexibility, hard work, taking up responsibility, cooperation, self-realization and knowledge acquisition.

The technical and professional teaching team of Wisconsin State has classified the life skills into: basic life skills that include the skills of communication, analytic life skills that include the identification of problems and solving them scientifically, and effective skills that include citizenship, conflict management, profession development, studying skills and self-organization skills (Wisconsin Department, 2006).

Because of the importance of life skills among the university students, many researchers have studied them. The study of Schult \& Chweu (2012), entitled "The Effectiveness of a life skills program in a South African Higher Education Institution", has indicated that the institution needs the personal skills, academic skills, public relations and communication and the facilitation skills. Al-Hammouri (2002) has found a big weakness in the 
students' practice of studying behaviors and skills because no studying skills were practiced properly. Hamdi's study (1998), entitled "The Relation between the skill of problem solving and Frustration among the university students", came up with the result that students' possessing of problem solving skills is weak.

The individuals' acquisition of life skills is a very important issue. Thus, the one who doesn't have life skills can't communicate with others and can't be happy or relaxed in his life. He can't also receive the appreciation from the society he lives in. hence, life skills enable the individual to communicate with others and execute his duties or charges successfully. It is the responsibility of the effective school to make students acquire the life skills through its different studying courses so that they can manage their life affairs. As a result of the importance of life skills and the problems many individuals are suffering from, many researchers have attempted to investigate the degree of having life skills among the students of a higher education institution in Jordan, which is the Hashemite University, considering it a distinguished university that introduces remarkable educational programs.

\section{Statement of the Problem}

Students' possessing of life skills makes the student the core of the teaching and learning process. Consequently, he/she becomes able to interact with others, and solve the problems he faces in scientific way. The problem of this study is represented by the identification of the Hashemite University students' possessing of life skills in light of some variables, and more specifically the problems entail answering the following questions:

Q1: What is the possessing degree of life skills among the Hashemite University students?

Q2: Are there statistically significant differences at the significance level of $(\boldsymbol{\alpha} \leq \mathbf{0 . 0 5})$ in the possessing degree of life skills among the Hashemite University students ascribed to the variable of gender?

Q3: Are there statistically significant differences at the significance level of $(\boldsymbol{\alpha} \leq \mathbf{0 . 0 5})$ in the possessing degree of life skills among the Hashemite University students ascribed to the variable of academic specialization?

Q4: Are there statistically significant differences at the significance level of $(\boldsymbol{\alpha} \leq \mathbf{0 . 0 5})$ in the possessing degree of life skills among the Hashemite University students ascribed to the variable of Academic level?

Q5: Are there statistically significant differences at the significance level of $(\boldsymbol{\alpha} \leq \mathbf{0 . 0 5})$ in the possessing degree of life skills among the Hashemite University students ascribed to the variable of GPA?

\section{Significance of the Study}

This study is important for the following reasons: (1) This study acquires its theoretical importance from the importance of life skills in the public life in achieving different goals for students regarding communication and cooperation with others, practicing work within one team, and providing him with the data and experiences needed for managing the different daily life situations. (2)This study provides those concerned with preparing studying plans with data and information for taking care of having life skills courses within their plans.(3)It opens the way for the researchers to conduct other studies for other variables rather than the ones addressed in this study.

\section{Methodology.}

\subsection{Population and Sample of the Study}

The population of this study consisted of (15230) undergraduate students, who were enrolled in the various faculties at Hashemite University (HU) for the academic year 2012/2013, across all levels of study. A sample population of (855) undergraduate, between the ages of 18-22 years old, were selected based on random sampling technique.

\subsection{Instruments:}

\section{Life Skills Questionnaire (LSQ).}

The instrument used in this study was developed by Wafie (2010). The instrument consisted of (30) items that relate to life skills in the three dimensions: communication skills (11) items, problem solving skills and decision making (10) items, academic skills (9) items. Participants rated each items on a 5 point ranging from totally disagree (1) to totally agree (5).

An internal consistency coefficient (0.77) was reported for the life skills instrument. In terms of the life skills scales, a reliability estimate of $(0.44)$ was reported for the communication skills, and $(0.60)$ was reported for the problem solving skills and decision-making, and (0.72) was reported for the academic skills. 
In this study, the reliability coefficient was calculated using test-retest and was found to be $(0.76,0.81$, and 0.79$)$ for communication skills, problem solving skills and decision making and academic skills respectively.

\subsection{Data Collection}

After acquiring the instructor permission, the questionnaire administrated was during regular class periods to student in the second semester of the 2012-2013 academic years. The students received written instruction that specified the purpose of the study and explained the procedure followed while responding to the questions. In particular, the students were told that there were no rights or wrong response. Students asked to return the questionnaires to the class instructor who passed them it on to the researcher.

\subsection{Data Analysis}

The data collected from all participants were coded, entered onto the SPSS spreadsheets, and analyses using software package SPSS version 17. Descriptive statistics for all variables in this study were examined using SPSS frequencies. The minimum and maximum values of each item were examined for accuracy of data entry by inspecting any out-of-range values. No out-of-range values were found. Missing subjects were not detected either. The results of the study are addressed by each objective.

\section{Results}

The results of the study are addressed by each question:

Q.1: What is the possessing degree of life skills among the Hashemite University students?.

To answer this question, means and standard deviations were calculated for the life skills included within the study tool. Those means explained the students' possession degree of life skills using the following ranges: less than 3 means low possession degree, 3-4 means medium possession degree, more than 4 means high possession degree, as indicated in table (1).

Table 1. Means \& SD for life skills among the study sample $(\mathrm{N}=855)$

\begin{tabular}{lllc}
\hline Life skills & Mean & SD & Possession degree \\
\hline Communication with others & 3.95 & 0.94 & Medium \\
Taking decision \& problem solving & 3.61 & 1.12 & Medium \\
Academic skills & 3.81 & 1.13 & Medium \\
Total & 3.79 & 1.06 & Medium \\
\hline
\end{tabular}

Table 1 clearly shows that the Hashemite University students' possession degree of life skills was medium with an average of (3.79). The first rank was occupied by the communication skills with a mean of (3.95), followed by the academic skills which had a mean of (3.8), and in the last rank came the skills of decision making and problem solving with a mean of (3.61).

Also, means and standard deviations were calculated for all of the items included in the study as seen below.

First: The skills of communicating with others:

Table 2. Means \& SD for the skills of communication among the study sample $(\mathrm{N}=855)$

\begin{tabular}{clccc}
\hline No. & \multicolumn{1}{c}{ Item } & Mean & SD & Possession degree \\
\hline 1 & I like to talk with others even if they were foreigners. & 3.81 & 0.95 & Medium \\
2 & I like seminars and workshops regarding communication with others & 3.77 & 0.94 & Medium \\
3 & I use gestures and body language to clarify an idea for others. & 4.11 & 0.92 & High \\
4 & I may give up an opinion I'm convinced with for the sake of others. & 2.80 & 1.35 & Low \\
5 & I meet others smiling. & 4.32 & 0.93 & High \\
6 & I apologize for the one I hurt his feelings. & 4.41 & 0.85 & High \\
7 & I understand others' feelings and sympathize with them. & 4.45 & 0.62 & High \\
8 & I concentrate my attention towards what the speaker is saying. & 4.21 & 0.76 & High \\
9 & I find it difficult to praise or compliment others. & 3.37 & 1.22 & Medium \\
10 & I avoid interrupting others while speaking. & 3.95 & 0.98 & Medium \\
11 & I can build good relations with my university colleagues. & 4.29 & 0.82 & Medium \\
& Total & 3.95 & 0.94 & Medium \\
\hline
\end{tabular}


It is clear in Table 2 that the Hashemite University students' possession degree of the skills of communication with others was medium with an average of (3.95), where the means ranged from (4.45) as the highest degree to (2.80) as the lowest. The item of (I understand others' feelings and sympathize with them) got the first rank with a mean of (4.45), whereas the item of (I apologize for the one I hurt his feelings) got the second rank with a mean of (4.41). On the other hand, the $10^{\text {th }}$ rank was obtained by the item of (I find it difficult to praise or compliment others) with a mean of (3.37), whereas the last rank, the $11^{\text {th }}$, was obtained by the item (I may give up an opinion I'm convinced with for the sake of others) with a mean of (2.80).

\section{Second: The skills of decision making \& problem solving:}

Table 3. Means \& SD for the skills of decision making \& problem solving among the study sample $(\mathrm{N}=855)$

\begin{tabular}{clccc}
\hline No. & \multicolumn{1}{c}{ Item } & Mean & SD & Possession degree \\
\hline 1 & I handle reasons when having a problem. & 4 & 0.92 & High \\
2 & I suffer from lots of troubles and become confused. & 2.91 & 1.31 & Low \\
3 & Usually I help others in solving their problems. & 3.84 & 1.08 & Medium \\
4 & Ignorance of some problems may be a solution. & 2.64 & 1.30 & Low \\
5 & I suggest many solutions before choosing the proper one. & 3.77 & 1.06 & Medium \\
6 & When being angry, I take the right decisions. & 3.42 & 1.18 & Medium \\
7 & I examine reasons and arrange them until reaching the & 3.60 & 1.17 & Medium \\
& basic reason for the problem. & & & \\
8 & When the reasons are too many, I approach the solution. & 3.82 & 1.15 & Medium \\
9 & Solving a problem requires knowing its basic causes. & 4.25 & 1.02 & High \\
10 & If I am a leader of a group, my decisions will be correct. & 3.90 & 1.05 & Medium \\
& $\quad$ Total & 3.61 & 1.12 & Medium \\
\hline
\end{tabular}

It is clear in Table 3 that the Hashemite University students' possession degree of the skills of decision making and problem solving was medium with an average of (3.61), where the means ranged from (4.25) as the highest degree to (3.61) as the lowest. The item of (Solving a problem requires knowing its basic causes) got the first rank with a mean of (4.25), whereas the item of (I handle reasons when having a problem) got the second rank with a mean of (4). On the other hand, the $9^{\text {th }}$ rank was obtained by the item of (I suffer from lots of troubles and become confused) with a mean of (2.91), whereas the last rank, the $10^{\text {th }}$, was obtained by the item (Ignorance of some problems may be a solution) with a mean of (2.64).

\section{Third: The academic skills:}

Table 4. Means \& SDs for the academic skills among the study sample $(\mathrm{N}=855)$

\begin{tabular}{clccc}
\hline No. & \multicolumn{1}{c}{ Item } & Mean & SD & Possession degree \\
\hline 1 & I have got a studying timetable organizing my work. & 3.63 & 1.31 & Medium \\
2 & I use the pencil to highlight what is important when I am studying. & 4.05 & 1.16 & High \\
3 & I read the introduction when starting reading any book. & 3.52 & 1.29 & Medium \\
4 & I can study for a long time. & 3.49 & 1.27 & Medium \\
5 & I summarize the lecture during the class time. & 3.56 & 1.17 & Medium \\
6 & I review the lectures from time to time. & 3.52 & 1.14 & Medium \\
7 & I use the diagrams/charts to facilitate understanding. & 3.96 & 1.03 & Medium \\
8 & I divide the difficult parts in order to understand them. & 4.23 & 0.93 & High \\
9 & I review the answer before finishing the exam. & 4.33 & 0.95 & High \\
& Total & 3.81 & 1.13 & Medium \\
\hline
\end{tabular}

It is clear in Table 4 that the Hashemite University students' possession degree of the academic skills was medium with an average of (3.81), where the means ranged from (4.33) as the highest degree to (3.49) as the lowest. The item of (I review the answer before finishing the exam) got the first rank with a mean of (4.33), whereas the item of (I divide the difficult parts in order to understand them) got the second rank with a mean of 
(4.23). On the other hand, the $8^{\text {th }}$ rank was obtained by the item of (I review the lectures from time to time) with a mean of (3.52), whereas the last rank, the $9^{\text {th }}$, was obtained by the item (I can study for a long time) with a mean of (3.49).

Q.2: Are there statistically significant differences at the significance level of $(\boldsymbol{\alpha} \leq \mathbf{0 . 0 5})$ in the possessing degree of life skills among the Hashemite University students ascribed to the variable of gender?.

To answer this question, means and standard deviations were calculated, and T-test was also used to identify the differences significance according to the variable of gender as seen in Table 5.

Table 5. Means, SDs \& T-test results according to gender

\begin{tabular}{|c|c|c|c|c|c|c|}
\hline \multirow[t]{2}{*}{ Life skills } & \multicolumn{2}{|c|}{ Males $(N=275)$} & \multicolumn{2}{|c|}{ Females $(\mathrm{N}=580)$} & \multirow[t]{2}{*}{$\mathrm{T}$} & \multirow[t]{2}{*}{ Significance } \\
\hline & Mean & SD & Mean & SD & & \\
\hline Communication with others & 3.92 & 0.41 & 3.97 & 0.41 & -1.692 & 0.091 \\
\hline Decision making \& problem-solving & 3.62 & 0.45 & 3.59 & 0.37 & 1.161 & 0.246 \\
\hline Academic skills & 3.84 & 0.77 & 3.80 & 0.69 & 0.736 & 0.462 \\
\hline
\end{tabular}

It is clear in Table 5 that there were no statistically significant differences at the level $(\boldsymbol{\alpha} \leq \mathbf{0 . 0 5})$ in the students' possession degree of the skills of communication, decision making, problem solving and academic skills ascribed to gender.

Q.3: Are there statistically significant differences at the significance level of $(\boldsymbol{\alpha} \leq \mathbf{0 . 0 5})$ in the possessing degree of life skills among the Hashemite University students ascribed to the variable of academic specialization?

To answer this question, means and standard deviations were calculated, and T-test was also used to identify the differences significance according to the variable of academic specialty as seen in Table 6 .

Table 6. Means, SDs \& T-test results according to academic specialization

\begin{tabular}{lcccccr}
\hline Life skills & \multicolumn{2}{c}{$\begin{array}{c}\text { Humanitarian colleges } \\
(\mathrm{N}=435)\end{array}$} & \multicolumn{2}{c}{$\begin{array}{c}\text { Scientific colleges } \\
(\mathrm{N}=420)\end{array}$} & T & Significance \\
\cline { 2 - 5 } & Mean & SD & Mean & SD & \\
\hline Communication with others & 3.94 & 0.41 & 3.97 & 0.42 & -1.102 & 0.271 \\
$\begin{array}{l}\text { Decision making \& } \\
\text { problem-solving }\end{array}$ & 3.58 & 0.41 & 3.62 & 0.38 & -1.369 & 0.171 \\
Academic skills & 3.75 & 0.73 & 3.87 & 0.70 & 2.438 & $* 0.015$ \\
\hline
\end{tabular}

It is clear in Table 6 that there were no statistically significant differences at the level $(\boldsymbol{\alpha} \leq \mathbf{0 . 0 5})$ in the students' possession degree of the skills of communication, decision making, problem solving and academic skills ascribed to academic specialty, whereas there were statistically significant differences in the students' possession degree of the academic skills ascribed to the variable of academic specialization.

Q.4: Are there statistically significant differences at the significance level of $(\boldsymbol{\alpha} \leq \mathbf{0 . 0 5})$ in the possessing degree of life skills among the Hashemite University students ascribed to the variable of academic level?.

To answer this question, means and standard deviations were calculated, and One-Way ANOVA was also used to identify the significance of the differences according to the variable of academic level, as seen in Table 7 . 
Table 7. Means, SDs \& one-way ANOVA results according to academic level

\begin{tabular}{|c|c|c|c|c|c|c|}
\hline Variables & $\begin{array}{l}\text { Source of } \\
\text { Variance }\end{array}$ & $\begin{array}{l}\text { Sum of } \\
\text { Squares }\end{array}$ & $\begin{array}{l}\text { Degrees of } \\
\text { Freedom }\end{array}$ & $\begin{array}{l}\text { Mean of } \\
\text { Squares }\end{array}$ & $\mathrm{F}$ & $\begin{array}{c}\text { Significance } \\
\text { Level }\end{array}$ \\
\hline \multirow[t]{3}{*}{ Communication skills } & $\begin{array}{l}\text { Between } \\
\text { groups }\end{array}$ & 16.400 & 3 & 5.467 & 34.856 & $* 0.000$ \\
\hline & $\begin{array}{l}\text { Within } \\
\text { groups }\end{array}$ & 132.682 & 851 & 0.157 & & \\
\hline & Total & 149.082 & 854 & & & \\
\hline \multirow[t]{3}{*}{$\begin{array}{l}\text { Decision making \& } \\
\text { problem-solving skills }\end{array}$} & $\begin{array}{l}\text { Between } \\
\text { groups }\end{array}$ & 0.612 & 3 & 0.204 & 1.264 & 0.286 \\
\hline & $\begin{array}{l}\text { Within } \\
\text { groups }\end{array}$ & 136.583 & 851 & 0.161 & & \\
\hline & Total & 137.195 & 854 & & & \\
\hline \multirow[t]{3}{*}{ Academic skills } & $\begin{array}{l}\text { Between } \\
\text { groups }\end{array}$ & 10.680 & 3 & 3.560 & 6.983 & $* 0.000$ \\
\hline & $\begin{array}{l}\text { Within } \\
\text { groups }\end{array}$ & 431.288 & 851 & 0.510 & & \\
\hline & Total & 441.968 & 854 & & & \\
\hline
\end{tabular}

As seen clearly in Table 7, there were statistically significant differences at the level $(\alpha \leq 0.05)$ in the students' possession degree of the skills of communication, decision making, problem solving and academic skills ascribed to academic level, whereas there were no statistically significant differences in the students' possession degree of the communication skills ascribed to the variable of academic level, and to identify the significance of these differences, LSD test was utilized for post comparisons as seen in Table 8.

Table 8. Results of LSD test for post comparisons according to academic level

\begin{tabular}{ccccc}
\hline Studying level & First year & Second year & Third year & Fourth year \\
\hline $1^{\text {st }}$ year & & & & \\
$2^{\text {nd }}$ year & $*$ & $*$ & & \\
$3^{\text {rd }}$ year & $*$ & $*$ & & \\
$4^{\text {th }}$ year & $*$ & & & \\
\hline
\end{tabular}

This table indicates the existence of statistically significant differences in the possession degree of life skills according to the variable of academic level for the benefit of $3^{\text {rd }}$ and $4^{\text {th }}$ year students as compared to the students of the $1^{\text {st }}$ or $2^{\text {nd }}$ years.

Q.5: Are there statistically significant differences at the significance level of $(\boldsymbol{\alpha} \leq \mathbf{0 . 0 5})$ in the possessing degree of life skills among the Hashemite University students ascribed to the variable of GPA?

To answer this question, means and SDs were calculate. Also, One-way ANOVA was utilized to identify the differences significance according to the variable of GPA as seen in Table 9.

Table 9. Means, SDs \& one-way ANOVA results according to GPA.

\begin{tabular}{lcccccc}
\hline \multicolumn{1}{c}{ Variables } & $\begin{array}{c}\text { Source of } \\
\text { Variance }\end{array}$ & $\begin{array}{c}\text { Sum of } \\
\text { Squares }\end{array}$ & $\begin{array}{c}\text { Degrees of } \\
\text { Freedom }\end{array}$ & $\begin{array}{c}\text { Mean of } \\
\text { Squares }\end{array}$ & F & $\begin{array}{c}\text { Significance } \\
\text { Level }\end{array}$ \\
\hline Communication & Between groups & 3.417 & 3 & 1.139 & 6.642 & $* 0.000$ \\
skills & Within groups & 145.935 & 851 & 0.171 & & \\
& Total & 149.352 & 854 & & & $* 0.000$ \\
Decision making \& & Between groups & 7.161 & 3 & 2.387 & 15.621 & $*$ \\
problem-solving & Within groups & 130.035 & 851 & 0.153 & & \\
skills & Total & 137.195 & 854 & & & $*$ \\
Academic skills & Between groups & 34.241 & 3 & 11.414 & 23.812 & $* 0.000$ \\
& Within groups & 407.897 & 851 & 0.479 & & \\
& $\quad$ Total & 442.138 & 854 & & & \\
\hline
\end{tabular}


As seen clearly in table (9), there were statistically significant differences at the level $(\boldsymbol{\alpha} \leq \mathbf{0 . 0 5})$ in the students' possession degree of the skills of communication, decision making, problem solving and academic skills ascribed to GPA, and to identify the significance of these differences, LSD test was utilized for post comparisons as seen in table (10).

Table 10. Results of LSD test for post comparisons according to GPA.

\begin{tabular}{ccccc}
\hline Accumulative average & Excellent & Very Good & Good & Acceptable \\
\hline Excellent & & & \\
Very Good & $*$ & $*$ & \\
Good & $*$ & $*$ & \\
Acceptable & $*$ & & \\
\hline
\end{tabular}

This table indicates the existence of statistically significant differences in the possession degree of life skills according to the variable of GPA for the benefit of excellent and very good students as compared to the students whose average is good or acceptable.

\section{Discussion}

This study aimed at revealing the degree of the Hashemite University students' possession of life skills. The scale of life skills was implemented on the sample of the study. The results revealed that the Hashemite University students' possession of life skills was medium. The researchers ascribed that to the fact that students manifested the skills because of their study during the basic and secondary stages, and also because of the daily life experiences they have acquired and helped them in manifesting these skills, especially after transferring to the university life and being coexisted with that society. The researchers see that it is important to include courses that are related to life skills within every studying plan, focusing on the activation of the practical side when teaching students the life skills courses to enable students manifest these skills in their daily life. The results of this study are consistent with the studies of Al-Lolo (2005), Sa'd AlDeen (2007), Askaws (2005), and Al-Baghdadi (1995) which found that the level of life skills among students was below the required level. Regarding the variable of gender, the results indicated that there were no statistically significant differences in the Hashemite University students' possession degree of communication skills, decision making and problem-solving skills, and academic skills ascribed to the variable of gender. The researchers ascribed that to the fact that life skills are general skills because of the difference in social type in having them. Hence, students, both males and females, are exposed to life skills, and they interacted with the life during the same studying stages, without a difference in the teaching environments. The results of this study are also compatible with the results of Al-Sayed's (2007) study. Also, the findings revealed that there were no statistically significant differences in the students' possession degree of communication skills, and decision making and problem-solving skills ascribed to the variable of academic specialty, whereas there were statistically significant differences in the students' possession degree of academic skills ascribed to the variable of academic specialization. Researchers ascribed that to the difference in studying plans regarding the inclusion of courses related to life skills, as well as the variety of professors" schools which reflect on the students' possession of life skills, specifically the academic skills. Regarding the variable of studying level, the findings revealed the existence of statistically significant differences in the degree of possession of communication, and academic skills ascribed to the studying level, whereas there were no statistically significant differences in the possession degree of communication skills ascribed to the academic level. There were also significant differences in the possession degree according to the variable of studying level for the benefit of $3^{\text {rd }}$ and $4^{\text {th }}$ year students as compared to the $1^{\text {st }}$ and $2^{\text {nd }}$ year students. The researchers ascribed that to the fact that $3^{\text {rd }}$ and $4^{\text {th }}$ year students have been exposed to more experiences and courses than the $1^{\text {st }}$ and $2^{\text {nd }}$, and the maturity factor could play a basic role in the difference of possession degree. In addition, the results revealed the existence of statistically significant differences in the students' possession degree of communication, decision making, problem-solving and academic skills ascribed to the variable of GPA. That was justified by the fact that high average students are usually more aware and educated than the students of low averages.

In light of this study results, the researchers recommend the following: (1) the necessity of adding and increasing the number of life skills courses within all studying plans for all specialties. (2) Focusing on the practical sides of life skills during instruction.(3)Conducting other studies on other samples rather than the one addressed in this study, having an experimental mark. 


\section{Summary}

The findings of the study indicated that the students' possession of life skills in the Hashemite University was medium. The researchers assert the necessity of developing the studying plans within all specializations so as to include deeper courses of life skills.

\section{References}

Alawiye, C. (1990). Comparative Self- Concept Variances of Children in Two English-Speaking West African Nations. Journal of Psychology, 124(2), 169-178. http://dx.doi.org/10.1080/00223980.1990.10543214

Al-Baghdadi, M. (1999). Among the secondary school graduates in the northern Egyptian cities (Vol. 1, pp. 7-10). The $7^{\text {th }}$ conference of the Egyptian Society for Curriculum \& Instruction methods. The Secondary Education \& the $21^{\text {st }}$ Century Challenges.

Al-Hammouri, H. (2002). The Hashemite University Students' practicing degree of Studying Skills during the School Education Stage \& its Importance to them from their own point of view. Dirasat Journal Educational Sciences, 2(29), 34-44.

Al-Lolo, F. (2005). The Life Skills Included in the Palestinian Curriculum Content for the $1^{\text {st }} \& 2^{\text {nd }}$ Basic Classes. The $2^{\text {nd }}$ Educational Conference "The Palestinian Child between the Reality's Challenges and the Future Ambitions". College of Education, Islamic University-Ghaza.

Al-Sayyed, M. (2007). Al-Isra' University Students' Need for Life Skills. The Journal of Arab universities' Union, 49, 103-120.

Askaws, P. (2005). Developing the secondary stage students' life skills within the frame of future curriculum. The National Center for Educational Researches and Progress, Cairo.

Bastian, A., \& Veneta, A. (2005). Emotional Intelligence Predicts Life Skills, But Now As Well As Personality and Cognitive Abilities. Journal of Psychology, 15(2), 15-27.

Behrman, A. (2005). How about that Whole Child? Independent School, 65(1), 237-257.

Bellotti, M. (2005). Life Skill Project. The Journal of Correctional Education, 56(2), 96-100.

Danish, T., \& Steven, Y. (1997). New Roles for Sports Psychologists: Teaching Life Skills through Sport to At-Risk Youth. Quest Human Kinetics, 49(1), 100-140.

Habib, A. A. (2001). The Social Skills \& the Self-Efficacy among the excellent, normal and weak university students. Egyptian General Book Society, 4(57), 57-70.

Hamdi, N. (1998). The Relation between the skill of problem-solving \& depression among the university students. Dirasat Journal Educational Sciences, 25(1), 87-97.

Khatatneh, S. (2007). Building a Program for Training Mothers on Life Skills \& Investigating its Effect in Improving the Social Competency, the Self-Concept, and the Life Skills of their Children. Unpublished $\mathrm{PhD}$ Dissertation. Amman Arab University, Amman, Jordan.

Mahasneh, O. (2012). Emeregent Curricula and Based on the Place as a model for the American curricula and outcomes based curricula as a model for the Jordanian curricula. A Comperative study, Conference educational discourse and postmodern scientific conference arbitrator. Olive Private University, the Faculty of Arts.

Mahasneh, O. (2013). The Professional Education Curricula \& its instructional and assessment strategies (2nd ed.). Alam Al-Thaqafeh for publishing \& distributing, Amman, Jordan.

Ministry of Education. (2005). The General Reference Framework for the life skills-based learning. Amman, Jordan.

Ministry of Education. (2007). The Life Skills Training Guide. Amman, Jordan.

Sa'd AlDeen, H. (2007). The Life Skills included in the $10^{\text {th }}$ Grade Technology Curriculum \& the Students' Acquisition of it. Unpublished M.A. dissertation. Islamic University - Ghaza.

Schneider, J. (2004). Teaching Life Skills: Connecting With the Real World. Education Canada, 44(1), $24-25$.

Schultz, C., \& Chweu, M. (2012). The Value of a Life Skills Programmer at a Higher Education Institution in South Africa. International Review of Social Sciences and Humanities, 2, 190-199.

Subhi, A. E., \& Al-Shenawi, R. (2001). The Life Skills (1st ed.). Cairo, Zahra' Al-Sharq. 
UNICEF. (2005). What are the skills that are considered life skills? Retrieved from http://www.unicef.org/arabic/lifeskills/lifeskills25521.html

Waif, A. A. (2010). The Life Skills \& their Relation to Multiple Intelligence among the Secondary Stage Students in Ghaza. Unpublished M.A. Dissertation. Islamic University-Ghaza.

Wisconsin Department of Public Instruction, Career and Technical Education Team. (2006). Career \& Technical Education. Retrieved March 25, 2008, from http://www. dpi.state

\section{Copyrights}

Copyright for this article is retained by the author(s), with first publication rights granted to the journal.

This is an open-access article distributed under the terms and conditions of the Creative Commons Attribution license (http://creativecommons.org/licenses/by/3.0/). 